EDITORIAL

Rev Obstet Ginecol Venez. 2021; 81 (4): 311-313.

https://doi.org/10.51288/00810403

\title{
Open Researcher and Contributor Identification (ORCID) ¿Por qué registrarse?
}

\author{
D Dra. Mireya González Blanco
}

Directora/Editora

Durante todo el año 2020, en la actualización de las Normas de Publicaciones, incluimos dentro de las secciones del manuscrito, en la página del título, el envío del número de registro en el Open Researcher and Contributor Identification (ORCID), pero, al ser un requisito nuevo, lo acompañamos de un condicionante: "de poseerlo". Comenzamos así, a conversar con los autores para estimularlos a registrarse, conversaciones que no obtuvieron buena respuesta, en el sentido de que seguíamos recibiendo los manuscritos, sin el mencionado registro. A partir de número 2 de este año, decidimos modificar el planteamiento, y el condicionante "de poseerlo", que implicaba que era de carácter opcional, fue eliminado y sustituido por la palabra "obligatorio" y, sin embargo, para la publicación de este número 4 hemos tenido que demorar brevemente la publicación, siempre dentro del lapso establecido, con la finalidad de esperar por el registro de algunos de los autores cuyos documentos estaban incluidos para ser publicados.

Entendemos que todo cambio en los requisitos puede generar algo de resistencia, y que, en ocasiones la falta en el cumplimiento es por desinformación. De ahí que decidimos escribir brevemente sobre las razones por las que se solicita a los autores que se registren en la página de ORCID, que no es

Correo de correspondencia: rogvenezuela@gmail.com

Forma de citar este artículo: González Blanco M. Open Researcher and Contributor Identification (ORCID). ¿Por qué registrarse?. Rev Obstet Ginecol Venez. 2021; 81(4): 311-312. https://doi.org/10.51288/00810403 más que un código alfanumérico no comercial que identifica a investigadores a nivel mundial. Este código proporciona una identidad duradera para personas, similar a aquellos que son creados para entidades de contenido relacionado con las redes digitales, lo cual se hace a través de identificadores de objeto digital. El registro es un procedimiento sencillo y gratuito que evita errores de autoría por confusión de nombres o por cambio de apellidos en el tiempo.

Según la página web https://orcid.org (1), se trata de una organización global sin fines de lucro, que permite que todos los que participan en la investigación, la erudición y la innovación estén identificados de manera única y conectados con sus contribuciones a través de disciplinas, fronteras y tiempo. El ORCID es un identificador gratuito, único y persistente que el investigador posee y controla para siempre y que lo desambigua a él y a su trabajo porque distingue a quien lo posee de cualquier otro investigador, incluso de investigadores que comparten el mismo nombre, por lo que sus resultados y actividades de investigación se le atribuirán correctamente. El investigador puede conectar su número de ORCID con su información profesional: afiliaciones, subvenciones, publicaciones, revisión por pares y más, y usarla para compartir su información con otros sistemas, lo que garantiza que obtenga reconocimiento por todas sus contribuciones, eso ahorra tiempo y molestias, y reduce el riesgo de errores. 
En nuestra opinión, esto se traduce en varias ventajas prácticas:

La primera ventaja tiene que ver con la identificación inequívoca de los autores. Esto resalta la importancia de que el nombre del investigador y su producción científica, académica y profesional se asocien a la persona correcta. La verdad, hay investigadores cuyos nombre y apellidos son poco comunes y no enfrentan este problema, pero cuando vemos que la autora de un documento es González M, no podemos asegurar que es Mireya González, o María González, o Milagros González. Es más, incluyendo el nombre y dos apellidos, aún es posible que existan varias personas que compartan la misma identificación. Muchos dirán, incorporemos la cédula de identidad, pero se trata de poseer un identificador internacional.

En segundo lugar, y muy ligado al aspecto anterior, el ORCID permite normalizar nuestra firma científica, es decir, la forma en que decidimos firmar, de modo que nos identifiquen y nos distingan de otros. Es así que muchos de nosotros encontramos que en una publicación se nos identifica con el primer apellido y las iniciales del o los nombres, en otra se pueden incluir ambos apellidos, en ocasiones separados por un guion. Incluso, es posible que nos identifiquen solo por el segundo apellido. Si bien la firma científica es responsabilidad del investigador, muchas editoriales tienen normas estrictas respecto a la forma de identificar a los autores. La página de ORCID permite incorporar, no solo el nombre completo, sino todos los posibles nombres o formas de identificación que se han usado a lo largo del tiempo, lo que facilita que toda esa información también sea incorporada.

La tercera ventaja, tiene que ver con la posibilidad de incorporar en la página de ORCID toda la actividad científica, académica y profesional, de manera que se convierte en una especie de currículo digital disponible para ser difundido en cualquier momento y constantemente actualizado, proporcionando información sobre todas sus contribuciones a la ciencia, más allá de una simple lista de publicaciones. Ello permite hacer una valoración global del investigador, las líneas de investigación en las que trabaja, su continuidad en la producción científica y la colaboración habitual con instituciones nacionales o internacionales. Además, más allá de ello, permite preservar, divulgar y localizar la actividad científica, garantizando que los resultados de la investigación no se atribuyan a otra persona. A esto se le agrega el que exista un vínculo para importar los datos automáticamente, es decir, cada nueva publicación en la que aparezca su nombre vinculado a su registro ORCID, el autor recibe un correo donde se le pregunta si desea incorporarla a su perfil y, de aprobarlo, se incorpora en forma automática.

Finalmente, muchos editores y bases de datos están exigiendo el registro ORCID, de manera que, para incorporar una publicación en una base de datos como SciELO (Scientific Electronic Library Online), es necesario que las revistas exijan a sus autores cumplir con ese requisito. También es necesario para solicitar financiamiento para la investigación.

La única información que ORCID requiere para registrarlo es el nombre y dirección de correo electrónico, para fines de identificación básica y para garantizar que la cuenta sea única para la dirección de correo electrónico. Durante y después del registro, se puede elegir si se desea agregar más información a la cuenta, lo que puede hacer el investigador mismo o un tercero de confianza a quien le permita hacerlo. Cualquier dato agregado al registro ORCID es permanente hasta que sea eliminado, ya sea por el titular de la cuenta o por una parte de confianza, o hasta que desactive la cuenta ORCID. Es importante considerar que el vínculo para importar los datos automáticamente, es útil solo para la información asociada a su número de registro, es decir, cada nueva publicación puede ser incorporada a su perfil, pero las publicaciones 
anteriores a su registro deben ser incorporadas en forma manual.

Aquí es importante destacar un vicio que hemos venido observando. Muchos investigadores se registran, por la necesidad de proporcionar la identificación ante la exigencia del Comité Editorial, sin embargo, no incorporan la información de sus publicaciones y record académico y profesional. Al entrar en la página es posible observar que muchos registros llegan hasta la obtención del número, con lo cual se pierde la tercera ventaja del ORCID, de gran valor no solo individual sino para la comunidad científica, en general.
Por último, es importante destacar que ORCID integra todos los sistemas de identificación de autores que se han ido generando a lo largo del tiempo: research ID, Scopus, entre otros, por lo que pareciera que está llamado a ser el sistema de identificación único de autores.

\section{REFERENCIAS}

1. ORCID. Connecting Research and Researchers [Internet]: About: Our Mision; s/f [consultado 28 de noviembre de 2021]. Disponible en: https://info. orcid.org/what-is-orcid/ 